\title{
Application of non-metallic composite reinforcement for contact line supports
}

\author{
Valery Nikolaev ${ }^{1}$, Valentina Stepanova ${ }^{2}$, and Vyacheslav Falikman ${ }^{3, *}$ \\ ${ }^{1}$ Composite building materials Assoc., 109428 Moscow, Russia \\ ${ }^{2}$ Scientific Research Institute for Concrete and Reinforced Concrete, 109428 Moscow, Russia \\ ${ }^{3}$ Structural Concrete Assoc., 109428 Moscow, Russia
}

\begin{abstract}
The technology for pre-stressing and anchoring of the composite rebar was developed. It makes possible to reinforce concrete products and produce the contact line supports of high quality, which possesses advantages in comparison with the steel reinforced concrete. The prototypes of supporting structures with the use of the composite BFRP reinforcement were developed. They were tested for strength, rigidity and crack resistance. In the course of testing, the value of a pole deflection in the plane of the application of the control load was determined. Poles with composite reinforcement (with vibratory load and after vibratory load) and steel reinforced poles were tested and compared. Results obtained show that the vibratory load had no significant impact on the properties of supports reinforced with pre-stressed composite rebars and confirm the practical possibility to use them. In the future, it is necessary to develop the working drawings for the replacement of the steel reinforcement by a composite polymer rebar and the technical requirements for supports of the contact lines of Russian Railways as well as the technical regulations for their design and manufacturing.
\end{abstract}

\section{Introduction}

In recent years, many types of composite polymer reinforcements have appeared on the construction market. However, the number of concrete structures made with its application is growing very slowly. One of the reasons is the lack of completed testing of experimental structural concrete for real operating conditions [1]. Noting the positive properties of the reinforcement, its disadvantage, i.e. low modulus of elasticity compared to steel reinforcement, is often indicated [2]. This property and a distinctive feature of the composite reinforcement may be exploited to the greatest possible extent in prestressed structures.

The supporting structures for overhead line conductors are various types of poles and towers called line support. In general, the line supports should have the following properties: high mechanical strength to withstand the weight of conductors and wind loads etc.; light in weight without the loss of mechanical strength; cheap in cost and economical to maintain, and with longer life.

The reinforced concrete poles have become very popular as line support in recent years. They have greater mechanical strength, longer life and permit longer spans than steel. Moreover, they give good outlook, require little maintenance and have good insulating properties.

* Corresponding author: vfalikman@yandex.ru 
Nevertheless, it is known that reinforced concrete line supports are subject to electrochemical corrosion caused by stray currents. In this regard, the lighter diamagnetic composite reinforcement, which is a dielectric and effectively works in structures under the influence of aggressive environments, is extremely attractive.

\section{Experiment design}

Within the framework of the RUSNANO project, the prototypes of supporting poles with rod reinforcement by prestressed composite basalt fiber polymer reinforcement having diameter of $16 \mathrm{~mm}$, with a tensile strength of $1000 \mathrm{MPa}$ and the modulus of elasticity of 50 GPa produced by JSC "RPP", Cheboksary (BFRPR) were developed and manufactured under production conditions at Meleuzovsky plant of reinforced concrete structures (MZZhBK) in the city of Meleuz, the Republic of Bashkortostan. Ordinary concrete of compressive strength class B40, frost resistance mark F150 was used for concreting. These support poles corresponded to the requirements of GOST 19330-2013 [3]. A total of six composite reinforced supports and two steel reinforced supports were manufactured; their characteristics are shown in Table 1.

Table 1. Characteristics of the tested prototypes of contact line supports

\begin{tabular}{|c|c|c|}
\hline Supports No. & Reinforcement & Prestressing conditions \\
\hline $1-6$ & $\begin{array}{r}\text { Prestressed composite bars, } \\
12 \text { rods } \varnothing 15.7 \mathrm{~mm}\end{array}$ & $1080 \mathrm{kN}$ \\
\hline 7 & $\begin{array}{c}\text { Prestressed steel bars, steel A-IV (A600), } \\
12 \text { rods Ø } 14 \mathrm{~mm} 1080\end{array}$ & $1080 \mathrm{kN}$ \\
\hline 8 & $\begin{array}{c}\text { Non-stressed steel bars, steel A-III (A400), } \\
8 \text { rods Ø } 14 \mathrm{~mm}\end{array}$ & - \\
\hline
\end{tabular}

For prestressing of composite reinforcement, special anchoring devices were used which enable the rebar to be reliably anchored with more than $40 \%$ rupture load and which provide its quick replacement [4]. Figure 1 shows a photo of a reinforcing frame with anchors.

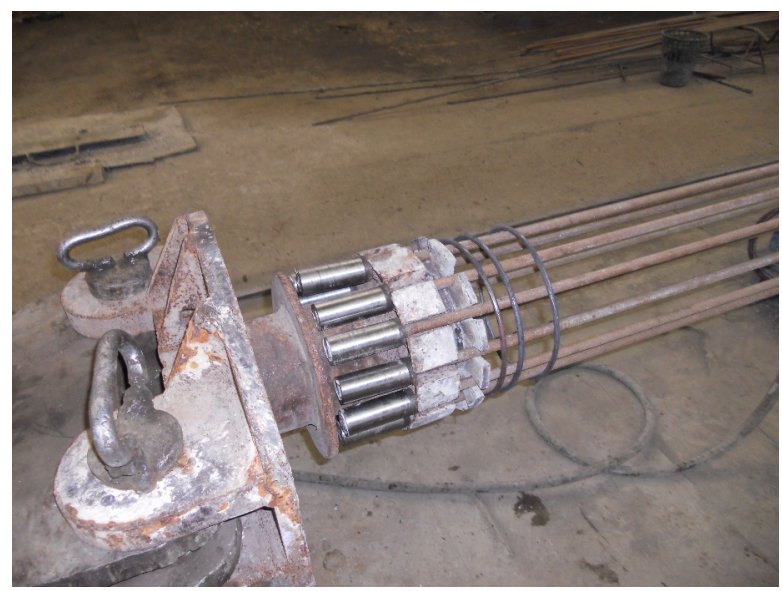

Fig. 1. Reinforcing frame with anchors 
Supports №1 and №2 were used for bench testing at MZZhBK. Immediately after their production, the supports with the composite reinforcement marked №3 and №6 were transported for resource testing to the Scientific Research Institute for Railway Transport (VNIIZhT) located in the city of Shcherbinka, Moscow region. After they have been tested, they were returned to Meleuz. Control poles №4 and №5 with the composite reinforcement, as well as a pair of steel reinforced concrete poles №7 and №8 were used for resource tests, as compared with the results of VNIIZhT.

Life (resource) tests were carried out by vibration loading of poles. During vibration loading, the load was applied to the console, the working length of which was $2.5 \mathrm{~m}$, installed at a height of $8 \mathrm{~m}$ from the base of the support. The static load was $2.25 \mathrm{kN}$, dynamic one was $6 \mathrm{kN}$, and the oscillation frequency was $0.5-0.7 \mathrm{~Hz}$. The number of loading cycles was 1000000 . The load application diagram is shown in Figure 2.

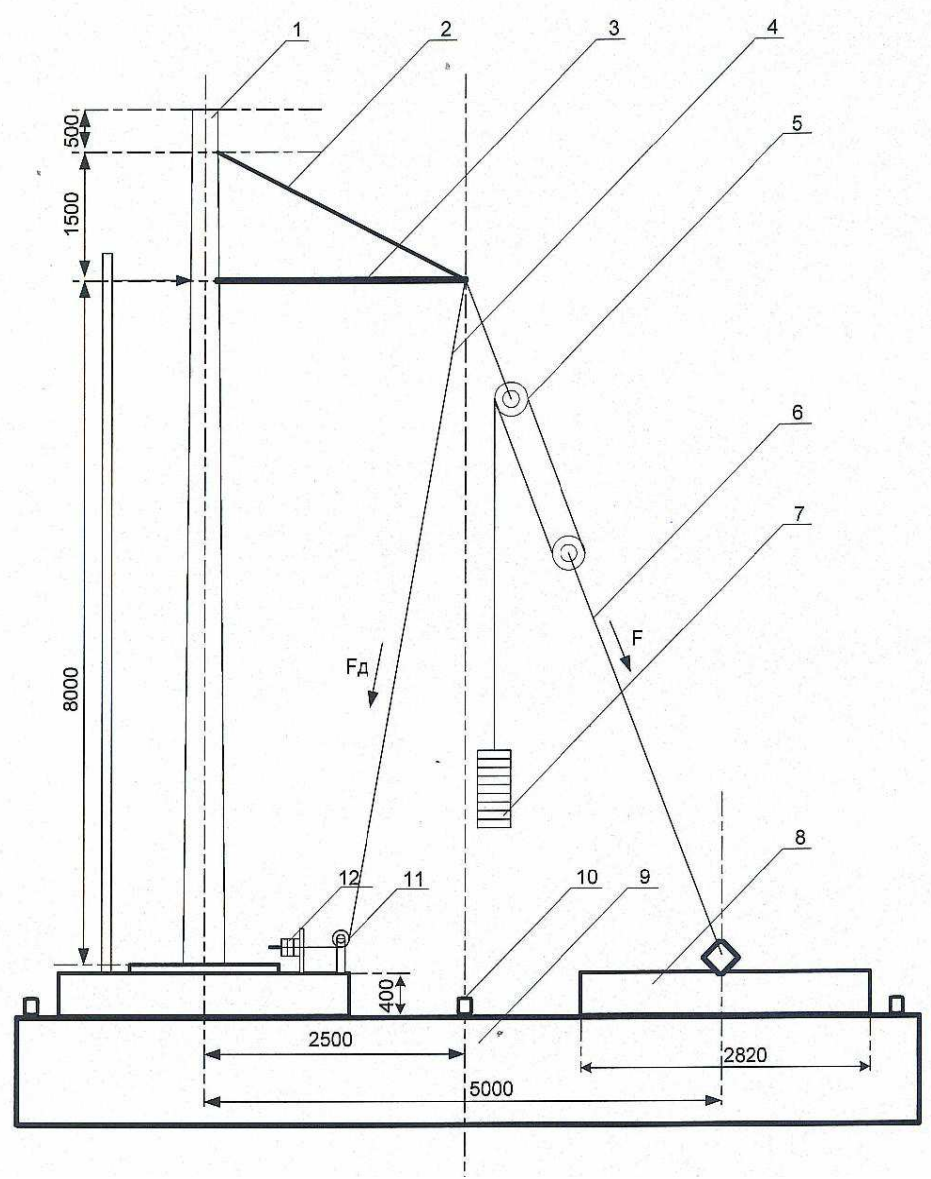

Fig. 2. Scheme of pole vibration loading

1 - pole; 2 - console; 3 - console draglink; 4 - cable; 5 - polyspast; 6 - guy wire;

7 - loads; 8 - plate; 9 - base; 10 - eye; 11 - roller; 12 - pulsator.

The dynamic load was created using a pulsator (Figure 3 ). 


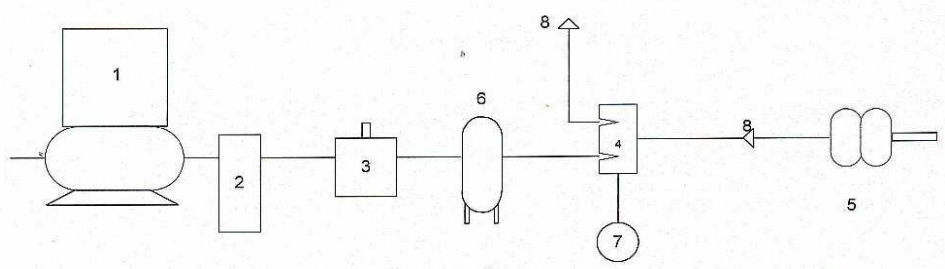

Fig. 3. Block diagram of the pulsator

1 - compressor with receiver; 2 - filter; 3 - pressure regulator; 4 - pneumatic distributor;

5 - pneumatic cylinder; 6 - receiver; 7 - control timer; 8 - vibration damper.

Prior to vibration loading, tests were performed to determine the straightness and stiffness of the poles. For supporting №3 (Table 1), deviation from straightness was $4 \mathrm{~mm}$ (not more than $10 \mathrm{~mm}$ according to GOST); deviation from the level of the contact wire (CWL) when applying the standard bending moment was $61 \mathrm{~mm}$ (not more than $125 \mathrm{~mm}$ according to GOST). For supporting №6, these results were $4 \mathrm{~mm}$ and $67 \mathrm{~mm}$, respectively. During vibration loading, the number of loading cycles and the poles' deviation from the straightness position at the level of the contact wire under static load were recorded (Table 2).

Table 2. Pole deflections depending on loading cycles at the level of the contact wire under static load

\begin{tabular}{|c|c|c|c|}
\hline \multirow{2}{*}{$\begin{array}{l}\text { Number of loading cycles, } \\
\text { thousands }\end{array}$} & \multicolumn{2}{|c|}{$\begin{array}{l}\text { Deviation from the unloaded state } \\
\text { at static load, } \mathrm{mm}\end{array}$} & \multirow{2}{*}{ Remarks } \\
\hline & Support № 3 & Support № 6 & \\
\hline 0 & 0 & 0 & Without load \\
\hline 0 & 72 & 62 & \\
\hline 0.25 & 81 & 75 & \\
\hline 50 & 86 & 79 & \\
\hline 100 & 86 & 85 & \\
\hline 150 & 86 & 87 & \\
\hline 200 & 87 & 89 & \\
\hline 250 & 87 & 91 & \\
\hline 300 & 87 & 92 & \\
\hline 350 & 88 & 93 & \\
\hline 400 & 88 & 94 & \\
\hline 450 & 88 & 93 & \\
\hline 500 & 88 & 92 & \\
\hline 550 & 88 & 93 & \\
\hline 600 & 88 & 93 & \\
\hline 650 & 88 & 93 & \\
\hline 700 & 89 & 93 & \\
\hline 750 & 90 & 104 & \\
\hline 800 & 90 & 105 & \\
\hline 850 & 91 & 113 & \\
\hline 900 & 91 & 113 & \\
\hline 950 & 92 & 113 & \\
\hline 1000 & 92 & 109 & \\
\hline 1000 & 16 & 35 & $\begin{array}{l}\text { Removing } \\
\text { of static load }\end{array}$ \\
\hline
\end{tabular}


Poles bench tests by loading to evaluate their strength, stiffness and crack resistance were carried out. The pole deflection magnitude was determined in the plane of the control load application, with an accuracy of $1 \mathrm{~mm}$ for every stage of the design loads at the CWL.

The load was applied to the test poles in stages of $0.1,0.2,0.4,0.6,0.8,0.9,0.95$ and $1.0 \mathrm{M}^{\mathrm{N}}\left(\mathrm{M}^{\mathrm{N}}\right.$ is normative load), having the initial pole position $\left(\mathrm{P}^{\mathrm{N}}\right)$ on CWL, previously fixed with a ruler. The pole was maintained after each load stage was applied for 10 minutes, up to the value of $1.0 \mathrm{M}^{\mathrm{N}}$. At this stage, the loads fixed the final pole position $\left(\mathrm{P}_{\mathrm{F}}\right)$ against CWL. The pole deflection was calculated using the formula $\Delta \mathrm{P}=\mathrm{P}_{\mathrm{N}}-\mathrm{P}_{\mathrm{F}}$ according to the measured values of the pole positions on CWL. Subsequently, the load on the pole was increased by steps of $1.05,1.1,1.2,1.3,1.4,1.5$ and $1.6 \mathrm{M}^{\mathrm{N}}$. The pole was considered to have passed the test, if the pole did not collapse under the load corresponding to $\mathrm{K}_{\mathrm{saf}}=$ 1.6 .

Tests were carried out in accordance with GOST 19330 for two poles reinforced with the composite reinforcement that passed vibration loading, for two poles reinforced with the composite reinforcement without vibration loading, and for two new steel reinforced concrete poles without vibration loading. Generalized data on steel reinforced concrete poles and poles reinforced with composite bars are given in Table 3.

Table 3. Results of contact network supports in mechanical tests

\begin{tabular}{|c|c|c|c|c|c|c|}
\hline \multirow{3}{*}{$\begin{array}{c}\begin{array}{c}\text { Description, } \\
\text { measurable indicator }\end{array} \\
\text { Poles №№ }\end{array}$} & \multicolumn{4}{|c|}{ Poles without vibration loading } & \multirow{2}{*}{\multicolumn{2}{|c|}{$\begin{array}{c}\text { Poles reinforced with } \\
\text { composite bars that } \\
\text { passed vibration } \\
\text { loading }\end{array}$}} \\
\hline & \multicolumn{2}{|c|}{$\begin{array}{l}\text { Poles reinforced with } \\
\text { composite } \\
\text { reinforcement }\end{array}$} & \multicolumn{2}{|c|}{$\begin{array}{l}\text { Steel reinforced } \\
\text { concrete poles }\end{array}$} & & \\
\hline & 4 & 5 & 7 & 8 & 3 & 6 \\
\hline $\begin{array}{c}\text { Deflection at CWL } \\
\text { under load of } 1.0 \mathrm{M}^{\mathrm{N}} \text {, } \\
\text { mm (not more than } 125 \\
\text { mm according to } \\
\text { GOST) }\end{array}$ & 99 & 90 & 82 & 73 & 91 & 89 \\
\hline Strength test $\left(1,6 \mathrm{M}^{\mathrm{H}}\right)$ & & & No de & ruction & & \\
\hline $\begin{array}{l}\text { Load corresponding to } \\
\text { the beginning of crack } \\
\text { formation, } \mathrm{kN}\end{array}$ & $\begin{array}{c}28.8 \\
\left(1.4 \mathrm{M}^{\mathrm{N}}\right)\end{array}$ & $\begin{array}{c}30.7 \\
\left(1.5 \mathrm{M}^{\mathrm{N}}\right)\end{array}$ & $\begin{array}{c}28.4 \\
\left(1.4 \mathrm{M}^{\mathrm{N}}\right)\end{array}$ & $\begin{array}{c}28.6 \\
\left(1.4 \mathrm{M}^{\mathrm{N}}\right)\end{array}$ & $\begin{array}{c}24.7 \\
\left(1.2 \mathrm{M}^{\mathrm{N}}\right)\end{array}$ & $\begin{array}{c}26.6 \\
\left(1.3 \mathrm{M}^{\mathrm{N}}\right)\end{array}$ \\
\hline $\begin{array}{l}\text { Load at which the crack } \\
\text { opening width is } 0.15 \\
\text { mm, kN }\end{array}$ & $\begin{array}{c}33.3 \\
\left(1.6 \mathrm{M}^{\mathrm{N}}\right)\end{array}$ & $\begin{array}{c}34.5 \\
\left(1.7 \mathrm{M}^{\mathrm{N}}\right)\end{array}$ & $\begin{array}{c}35.5 \\
\left(1.7 \mathrm{M}^{\mathrm{N}}\right)\end{array}$ & $\begin{array}{c}36.0 \\
\left(1.7 \mathrm{M}^{\mathrm{N}}\right)\end{array}$ & $\begin{array}{c}32.8 \\
\left(1.6 \mathrm{M}^{\mathrm{N}}\right)\end{array}$ & $\begin{array}{c}34.0 \\
\left(1.7 \mathrm{M}^{\mathrm{N}}\right)\end{array}$ \\
\hline $\begin{array}{l}\text { Load corresponding to } \\
\text { the pole destruction, } \mathrm{kN}\end{array}$ & $\begin{array}{c}40.3 \\
\left(2.0 \mathrm{M}^{\mathrm{N}}\right) \\
\end{array}$ & - & - & - & - & $\begin{array}{c}40.8 \\
\left(2.0 \mathrm{M}^{\mathrm{N}}\right) \\
\end{array}$ \\
\hline $\begin{array}{l}\text { Cracks closure after } \\
\text { removal of the load }\end{array}$ & 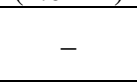 & Yes & Yes & Yes & Yes & - \\
\hline $\begin{array}{l}\text { Residual deformation } \\
\text { after load removing } \\
\text { (non-straightness) }\end{array}$ & - & 4 & - & - & 6 & - \\
\hline
\end{tabular}

For poles №4 and №6 reinforced with the composite reinforcement, the load was applied up to their destruction $(40.3 \mathrm{kN}$ and $40.8 \mathrm{kN}$, respectively), which corresponds to $2.0 \mathrm{M}^{\mathrm{N}}$. For poles №3 and №5 reinforced with the composite reinforcement, their straightness was checked after testing (6 $\mathrm{mm}$ and $4 \mathrm{~mm}$, respectively), which was within the limits allowed by the regulatory documentation (not more than $10 \mathrm{~mm}$ ). For all poles (except the collapsed ones), the cracks were closed after the loads were removed. 


\section{Conclusions}

In light of the above, the technology of prestressing and anchoring of composite polymer reinforcement of the high performance contact line supports, which have a number of advantageous characteristics in comparison with ordinary reinforced concrete structures, was developed and tested. The obtained results confirmed the possibility to use concrete poles reinforced with prestressed BFRP bars for the contact lines of Russian Railways.

The test results showed that the vibration loading did not have a significant impact on the properties of the supports reinforced with the composite reinforcement. During vibration loading, no visible damage of poles was detected; the deflection of a pole at the level of a contact wire resulting from the application of the standard bending moment was in admissible limits. Poles reinforced with the BFRPR, without vibration loading and undergoing vibration loading, comply with the GOST 19330 requirements for crack resistance. After vibratory loading and the application of verifying load, their straightness is restored. The straightness of the poles meets the requirements of the standards as well.

The deflection under the application of normative bending moment before and after vibration loading for the poles with the BFRPR also satisfies the requirements of standards. All tested poles provide the safety factor on structural failure before and after vibration loading established by the norms.

For the further development of the project, working drawings may be developed concerning the replacement of the steel reinforcement with composite polymer reinforcement. In addition, technical specifications for prospective supports of the Russian Railways contact lines, as well as technological regulations for their production may be drafted.

\section{References}

1. V.F. Stepanova, A.Yu. Stepanov, E.P. Zhirkov, Polymer composite reinforcement (ASV Publ., Moscow, 2013).

2. V.R. Falikman, V.F. Stepanova, Proceedings of the 4th International Conference on Service Life Design for Infrastructures (SLD4). Delft, the Netherlands. Publ. by RILEM Publications S.A.R.L. 1104p., pp. 1016-1025 (2018).

3. GOST 19330-2013 "Poles for railway contact line supports. Technical requirements" (2013).

4. V.N. Nikolaev, Patent 2203372 RU (2011). 